\title{
To the issue of assessing the efficiency of distributed generation in low-voltage electric networks
}

\author{
A.N. Alyunov ${ }^{1}$, A.Yu Belyanin ${ }^{1}, A . E$. Nemirovsky $^{1}$ and D.A. Zaripova ${ }^{2}$ \\ ${ }^{1}$ Vologda State University, Vologda, Russia \\ ${ }^{2}$ Kazan State Power Engineering University, Kazan, Russia
}

\begin{abstract}
This article considers an urgent task of using autonomous sources for power supply systems of industrial enterprises of small and medium-sized production. The efficiency of choosing the time of their switching-on in peak hours of power system in order to reduce the cost of electricity is shown on the example of diesel generators.
\end{abstract}

\section{Introduction}

At present the problem of increasing electricity tariffs for centralized electricity supply is brewing in some areas of industry. Statistical analysis over the past few years shows that the cost of electricity to the end consumer is increasing. The following factors have an influence on this trend:

- Transmission of electricity over long distances results in severe losses;

- Obsolete electrical equipment is still in operation;

- Electric networks have a lack of flexibility and mobility.

This problem can be solved by switching from centralized power supply to distributed generation. The main advantage of this process is production of electricity directly at the place of consumption, which guarantees optimal efficiency during its transportation [1-4].

The aim of the study is to assess the efficiency of distributed generation in low-voltage electric networks for production facilities.

Currently, in the Russian Federation, the primary consumers of electricity are industrial enterprises whose installed power range from several kilowatts to ten megawatts.

Today, the following categories of distributed generation can be considered:

1. Isolated generating plants.

2. Combined heat and power plants.

3. Diesel, gas turbine and gas piston power plants.

At first glance, these categories of distributed generation have more disadvantages than advantages for small production facilities.

To obtain the optimal saving effect from the use of a diesel generator when powering an object, the necessary condition is to come up to coincidence of hours the generator is turned on with hours of peak loads in power system and with hours of power take-off. Studies of electricity consumption schedules show that it is possible to reduce the cost of electricity and power in the specified hours [5].

For enterprises of small and medium-sized production it is inefficient to use large isolated generating plants, due to the lack of territory for their construction and significant costs for their construction and maintenance. In addition, many enterprises do not have gas distribution stations, substations and main gas pipelines in the immediate vicinity. One of the advantages of diesel power plants is the possibility of their widespread use, since diesel fuel is much more affordable than other types of fuel.

The comparative characteristics of diesel and gas power plants are presented in table 1 .

Diesel generators are oriented to longer work in comparison with gasoline generators. Gasoline generators can operate continuously for only a few hours and have power limitations.

Undoubtedly, to obtain the greatest economic effect, it is more expedient to switch to autonomous power supply using gas generators. However, due to significant one-time investments related to the commissioning of gas power plants for small and medium-sized productions, it is more rational to use diesel generators.

For any organization, the expenditures for purchasing electricity comprise a significant share in the cost of produced goods and services. All subjects of the Russian Federation according to the procedure for settlements for electricity can be divided into two groups:

- Zones of wholesale market in which the price of electricity is formed under competition;

- Non-price zones without competition, in which the price for electricity purchase is approved by the local executive body with authority in the field of tariff regulation.

It should be noted that the bulk of the electricity price is formed by the prices of transmission services, sales 
Table 1. Advantages and disadvantages of diesel and gas power plants.

\begin{tabular}{|c|c|c|}
\hline Power source & Advantages & Disadvantages \\
\hline Gas generators & $\begin{array}{l}\text { 1) The cost of a unit of generated electricity } \\
\text { is much lower than that of gasoline and } \\
\text { diesel generators; } \\
\text { 2) Low noise during operation; } \\
\text { 3) High environmental performance. }\end{array}$ & $\begin{array}{l}\text { 1) Gas is explosive fuel, the probability of ignition of } \\
\text { which is much higher than that of diesel fuel; } \\
\text { accordingly, it is necessary to observe special conditions } \\
\text { of operation, storage, transportation of fuel tanks; } \\
\text { 2) The relatively large dimensions of the installation; } \\
\text { 3) Obtaining special permission from the relevant } \\
\text { authorities to connect the unit to the gas pipeline; } \\
\text { 4) Temperature conditions for storage of gas fuel. }\end{array}$ \\
\hline Diesel generators & $\begin{array}{l}\text { 1) Low operation costs; } \\
\text { 2) A relatively high efficiency, within } 50 \% \text {; } \\
\text { 3) Low noise during operation; } \\
\text { 4) The ability to work in various weather } \\
\text { conditions; } \\
\text { 5) Compactness; } \\
\text { 6) Quick start, stable performance. }\end{array}$ & $\begin{array}{l}\text { 1) High cost of primary fuel; } \\
\text { 2) High requirements to the quality of diesel fuel; } \\
\text { 3) Load factor of diesel generator should be at least } 40 \% \text {; } \\
\text { 3) High power diesel generators require additional } \\
\text { installation of a ventilation system. }\end{array}$ \\
\hline
\end{tabular}

allowances and purchase prices of electricity in the wholesale electricity market [6], [7].

Currently, six price categories can be distinguished with different procedures for the formation of the final price for electricity. Practice shows that the right choice of price category can reduce the cost of purchasing electricity by up to 30 percent.

Using a diesel generator at the enterprise and turning it on during peak hours of power system allows one to get an additional effect by reducing expenditures for power purchase [8], [9].

\section{Materials and methods}

Consider the idea of implementation of own generation in a low-voltage electric network using the example of electricity consumed by a manufacturing enterprise for 1 month (December) [10].

The greatest economic effect can be achieved by reducing the payments for power. For this, it is necessary to turn on the diesel generator during peak hours (peak load monitoring hours), thereby reducing the amount of power paid for in the wholesale electricity market. For this purpose, it is necessary to simultaneously solve the problem of choosing the optimal power and strategy of the diesel generator [10].

Electricity consumption should be considered only during hours of power take-off, that is, during peak hours on working days of month.

For clarity, we present them in the average monthly load schedule during power take-off hours (Fig. 1).

The methods of mathematical statistics were used to study the $\mathrm{X}$ criterion, i.e. power at peak hours on working days of month.

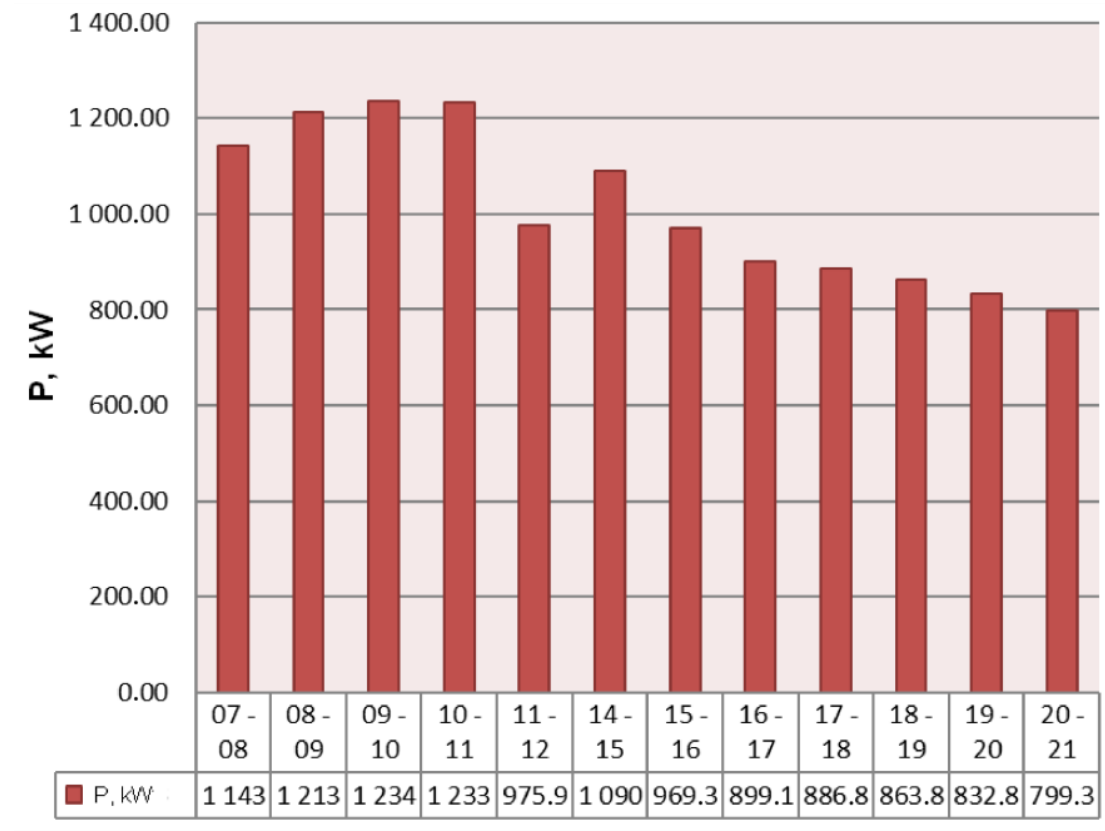

Fig. 1. Monthly average load schedule during power take-off hours (December) 
The average value (analog of mathematical expectation) of the investigated criterion is:

$$
\bar{x}=\frac{\sum_{k=1}^{i}\left(X_{k} \cdot m_{k}\right)}{n}=1011.52 \mathrm{~kW} .
$$

The variance is

$$
D=96097.76 k W^{2}
$$

The sample standard deviation is the most accurate variation indicator, which indicates by what value the entire set of random variables may differ from the average value (mathematical expectation):

$$
\sigma=\sqrt{96097.76}=310 \mathrm{~kW} .
$$

Based on the study, we determine the possible number of operation hours of the diesel generator, provided that the costs of the diesel generator will be covered by the cost of compensated power. The amount of paid power will be lower, and additional benefits will be achieved by reducing the amount of purchased electricity [10]:

$$
t=\frac{C_{W}+C_{N}}{C_{D} \cdot N_{D}} \approx 12 h,
$$

where $C_{W}$ is the purchase price of electricity in the wholesale electricity and power market, $\$ / \mathrm{kW} ; C_{N}$ is the system utilization charge of electrical networks of the selected tariff, $\$ / \mathrm{kW} ; C_{D}$ is the price of $\mathrm{kWh}$ of electricity generated by a diesel generator, $\$ / \mathrm{kW} \cdot \mathrm{h} ; N_{D}$ is the number of working days in a month.

Practice shows that to obtain additional savings, it is necessary to partially reschedule the work of production equipment from peak hours to another time, if the technological process enables this change.

\section{Results and discussion}

Thus, we find that the optimal number of operation hours of a diesel generator per day (in December according to the original schedule) is 12 hours. For the considered situation, by switching on the generator at the indicated hours, we are guaranteed to reduce both the amount of power paid in the wholesale market and the network power by the value of the nominal power of the diesel generator.

Based on the data obtained in the study, it can be argued that the diesel generator power should be selected from the condition:

$$
\sigma \leq P \leq 2.5 \cdot P_{M I N}, k W
$$

where $P_{\text {MIN }}$ is the minimum power consumption, $\mathrm{kW} ; \sigma$ is the standard deviation from average power, $\mathrm{kW}$

It is impractical to set power over $2.5 \cdot P_{M I N}$, since the load factor of a diesel generator in some hours will be less than $40 \%$, which will lead to accelerated wear of the internal mechanisms of unit.

We obtain that

$$
310 \leq P \leq 2.5 \cdot 407.45 \mathrm{~kW} .
$$

According to the range of standard power we accept $P=400 \mathrm{~kW}$. Given the generator's operating strategy for 12 hours a day during peak hours (from 8 to 12 hours and from 15 to 21 hours, inclusive), it is possible to determine the economic effect of using a diesel generator when reducing the power supply. However, turning on the unit for all 12 hours is irrational, therefore, it is necessary to determine the most probable reporting hours. Since peak hours are published at the end of the reporting period, the most probable hours should be determined based on statistical data over the past periods of time.

We denote $H$ as the peak load hour on working days of the considered December, obtained as a result of measurements and determine the numerical characteristics of the considered criterion $H$ :

$$
\begin{aligned}
& \text { mean } \bar{h}=\frac{1}{2} \sum_{i=1}^{21} h_{i} \\
& \text { variance } D(H)=\frac{1}{n} \sum_{i=1}^{21}\left(h_{i}-\bar{h}_{i}\right)^{2}=7.8 .
\end{aligned}
$$

We denote $Y$ as the peak hour on working days of another month (February) obtained as a result of observations. The determined numerical characteristics of the investigated characteristic $Y$ are:

$$
\begin{aligned}
& \text { mean } \bar{y}=\frac{1}{n} \sum_{j=1}^{20} y_{j}=10 \\
& \text { variance } D(Y)=\frac{1}{n} \sum_{j=1}^{20}\left(y_{j}-\bar{y}\right)^{2}=3.55 .
\end{aligned}
$$

We use the Pearson's chi-squared test, as one of the most frequently used in studies, to test the hypothesis that the peak hour of the load is the same in different months. This fact allows us to judge that the populations from which the samples are extracted are the same, so they have the same distribution law. The description of the experimental data using the well-known distribution law makes it possible to present the probability density function and the distribution function in an analytical form. This is useful in finding the probability of falling into a certain interval of the real peak load hours. [11].

Table 2 shows peak hour data. $h_{i}$ in December and $y_{i}$ in February, as well as the number of working days in which this hour took place.

Further we calculate the empirical value of chisquare:

$$
\chi_{E}^{2}=M \cdot N \sum_{i=1}^{l} \frac{\left(\frac{h_{i}}{M}-\frac{y_{i}}{N}\right)}{h_{i}+y_{i}} \approx 11.44
$$


Table 2. Statistics of peak hours

\begin{tabular}{|c|c|c|}
\hline Peak hour & $\boldsymbol{h}_{\boldsymbol{i}}$ & $\boldsymbol{y}_{\boldsymbol{i}}$ \\
\hline 8 & 0 & 2 \\
\hline 9 & 3 & 9 \\
\hline 10 & 5 & 5 \\
\hline 11 & 10 & 1 \\
\hline 17 & 0 & 0 \\
\hline 18 & 3 & $N=\sum_{j=1}^{6} y_{i}=20$ \\
\hline
\end{tabular}

Using the chi-square table for the number of degrees of freedom $k=l-1=6-1=5$, we find the probability that, due to random reasons (rather than sample homogeneity), the value $\chi^{2}$ will be not less than empirical value [11]

The found probability is quite small, therefore, the hypothesis of uniformity of samples, indicating the same choice of peak hour of power system every month using the Pearson criterion chi-square, is rejected. In addition, the spread of obtained numerical characteristics speaks in favor of different distribution of peak hour of power system in the indicated months. Studies based on probabilistic and statistical methods show that the choice of optimal hour is irrational.

Therefore, it is necessary to determine the time interval for the strategy of own generation. When choosing the optimal solution, other power characteristics in low-voltage electric networks can be taken into account, for example reactive power [12].

\section{References}

[1] K.S. Sambaiah, T. Jayabarathi, Optimal reconfiguration and renewable distributed generation allocation in electric distribution systems, International Journal of Ambient Energy (2019). DOI: 10.1080/01430750.2019.1583604.

[2] S. Kansal, B. Tyagi, V. Kumar, Cost-benefit analysis for optimal distributed generation placement in distribution systems, International Journal of Ambient $\begin{array}{llll}\text { Energy } & 38 & \text { (2017). }\end{array}$ 10.1080/01430750.2015.1031407.

[3] E. Sukhareva, A. Fedyukhin, O. Derevianko, M. Egorov, L. Mukhametova, I. Akhmetova, Optimization of combined heat and power plant operating mode by means of underutilized equipment mothball, IOP Conference Series: Earth and Environmental Science 288, 1, 012122 (2019).

[4] A.A. Sinitsyn, N.N. Boytsova, I.G. Akhmetova, S.O. Makoev, A. Asadpoori, O.A. Stepanov, N.V. Rydalina, E.O. Antonova, B.G. Aksenov, Study of operation of power-generating devices of gaseous fuels combustion, International Journal of Mechanical Engineering and Technology 10, 2, 1480-1490 (2019).

[5] A. Jabbary, H. Shayeghi, Smart imposing of operational limits in optimising the technical and economic indexes of a distribution network in the presence of distributed generation sources, International Journal of Ambient Energy (2018). DOI: 10.1080/01430750.2018.1492451.

[6] J. Salehi, M. R.J. Oskuee, Optimal planning of distributed generation from the DisCo and the DGO viewpoints considering the uncertainties in future demand and electricity price, International Journal of Ambient Energy 39 (2018).

[7] N. John, V. Janamala, J. Rodrigues, Impact of Variable Distributed Generation on Distribution System Voltage Stability, International Conference on Data Science and Communication (IconDSC), Bangalore, India, $1-5 \quad$ (2019). DOI: 10.1109/IconDSC.2019.8817028.

[8] F.R.A. Bukit, N. Mubarakah, D.M. Nasution, Minimizing The Electrical Power Distribution Cost By Optimizing the Distributed Generation Placement, 3rd International Conference on Electrical, Telecommunication and Computer Engineering (ELTICOM), Medan, Indonesia, 60-65 (2019). DOI: 10.1109/ELTICOM47379.2019.8943868.

[9] V.V. Dubaylova, N.D. Mukhlynin, O.J. Polyakova, Distributed Generation Control in Energy Market Conditions Using Advanced Model Predictive Control, 16th Conference on Electrical Machines, Drives and Power Systems (ELMA), Varna, Bulgaria, 1-4 (2019). DOI: 10.1109/ELMA.2019.8771696.

[10] A.N. Alyunov, V.A. Babarushkin, IT service for energy saving in power supply systems, Energyefficient technologies in a modern institution, International Energy Forum (2013).

[11] O.I. Mikryukova, S.V. Ivanova, A.Yu. Belyanina, Nonparametric criteria for testing statistical hypotheses (Vologda State University, Vologda, 2017).

[12] D. Matvoz, R. Leskovec, M. Maksić, Optimized reactive power characteristics for distributed generation sources in the low voltage network, IEEE Manchester PowerTech, Manchester, 1-6 (2017). DOI: 10.1109/PTC.2017.7981070. 